\title{
A comunidade Mumbuca e as plantas medicinais: tecendo aproximações entre saberes tradicionais e ensino de química
}

\author{
Mumbuca's community and medicinal plants: possible approximations \\ between traditional knowledges and chemistry teaching
}

Junio Gonçalves de Almeida

Mestre

Universidade Federal do Tocantins - UFT.

Gurupi, TO - Brasil.

almeida.juniog@gmail.com

Welington Francisco

Doutor

Universidade Federal da Integração Latino-Americana - UNILA.

Foz do Iguaçu, PR - Brasil.

welington.francisco@unila.edu.br

\begin{abstract}
Resumo: Uma vez que os saberes tradicionais são atribuídos a pequenos grupos ou sociedades que reproduzem historicamente seu modo de vida, apresentando diversos conhecimentos, o objetivo deste trabalho foi identificar os saberes da comunidade Mumbuca acerca do uso medicinal de plantas, a fim de buscar correlações com os conhecimentos químicos e viabilizar atividades de ensino. Realizou-se uma pesquisa etnográfica, com coleta de dados por meio de entrevista com a matriarca da comunidade e registros de campo durante o tempo passado com o povoado. A análise dos resultados aponta para uma diversidade de saberes tradicionais relacionado às plantas medicinais, que vão desde uma variedade de espécies utilizadas até a seleção da planta para preparação de chás e/ou garrafadas. Esses saberes possibilitaram a interrelação com muitos conhecimentos químicos, propiciando a proposição de uma atividade de ensino para uma formação mais integral.
\end{abstract}

Palavras chave: conhecimento tradicional; caso investigativo; plantas medicinais; ensino de química.

Abstract: Once the traditional knowledges represent the life way and the knowledge of different groups and societies, this work aimed identify these knowledges of Mumbuca community about of the use the medicinal plants in order to seek connections with chemical concepts and elaborate activities that mix the different knowledges. From of an ethnographic research, it collected the data through an interview with the community matriarch and field records. The analysis of the results points to a diversity of traditional knowledges related to medicinal plants, ranging from a variety of species to the selection of the plant for preparing teas and/or bottles, which allowed the interrelation with many knowledges to develop teaching activities for more comprehensive training.

Key-words: traditional knowledge; investigative case; medicinal plants; chemistry teaching.

Cite como

(ABNT NBR 6023:2018)

ALMEIDA, Junio Gonçalves; FRANCISCO, Welington. A comunidade Mumbuca e as plantas medicinais: tecendo aproximações entre saberes tradicionais e ensino de química. Dialogia, São Paulo, n. 39, p. 1-19, e20241, set./dez. 2021. Disponível em: https://doi.org/10.5585/39.2021.20241.

American Psychological Association (APA)

Almeida, J. G., \& Francisco, W. (2021, set./dez.) A comunidade Mumbuca e as plantas medicinais: tecendo aproximações entre saberes tradicionais e ensino de química. Dialogia, São Paulo, 39, p. 1-19, e20241. https://doi.org/10.5585/39.2021.20241. 


\section{Introdução}

A partir da década de 90, os conhecimentos tradicionais despertaram interesse em comunidades científicas e passaram a ganhar maior visibilidade no contexto educacional. Assim, diversos trabalhos buscaram correlacionar os conhecimentos tradicionais com os conhecimentos científicos, destacando-se:

- Os saberes tradicionais sobre o tear de quatro pedais de artesãs no Centro de Fiação e Tecelagem de Uberlândia (GONDIM, 2007);

- A relação entre os conhecimentos químicos e a fabricação de sabão de cinzas no interior de Minas Gerais (PINHEIRO; GIORDAN, 2010);

- O desenvolvimento de atividades voltadas à produção artesanal de vinho de laranja com estudantes do terceiro ano do Ensino Médio no município de São Tiago - MG (RESENDE; CASTRO; PINHEIRO, 2010);

- A aproximação da prática cultural de produção de cachaça na cidade de Abaíra (BA), por meio de um projeto construído em âmbito escolar com estudantes do ensino fundamental e ensino médio (ALMEIDA, 2012);

- A descrição do conhecimento tradicional sobre plantas medicinais junto à Três Unidades de Saúde da Família (USF) no interior de São Paulo para um diálogo que fundamentava a prática humana e integral (ALCANTARA; JOAQUIM; SAMPAIO, 2015);

- A proposição de um plano pedagógico com os detentores e transmissores da história quilombola, conhecidos como Griôs, aproximando as diferentes formas de compreensão do mundo (tradicional e científica) voltadas ao ensino de química (SANTOS; CAMARGO; BENITE, 2020).

Nessa seara, percebe-se que a característica em comum entre esses trabalhos é a presença de grupos específicos. Em 2007, o Decreto 6.040 instituiu a Política Nacional de Desenvolvimento Sustentável dos Povos e Comunidades Tradicionais, atribuindo a esses povos uma constituição autêntica com formas de organização sociais próprias como: utilização dos recursos naturais como forma de subsistência; posse de manifestação cultural, social, religiosa, ancestral e econômica; e uso de seus conhecimentos tradicionais transmitidos oralmente por gerações (BRASIL, 2007). Neste trabalho, a comunidade tradicional participante foi a Mumbuca.

Trata-se de uma comunidade quilombola formada há mais de um século a partir da miscigenação de negros e índios, onde vivem aproximadamente 169 pessoas de 52 famílias (CAVALCANTE, 2018). Está situada a $35 \mathrm{~km}$ do Município de Mateiros - TO e é um dos 
principais destinos turísticos para a prática do ecoturismo. Desde 2001, os "Mumbucas" foram incorporados ao Parque Estadual do Jalapão (PEJ), uma Unidade de Conservação de Proteção Integral.

De acordo com Diegues (2004), a Comunidade Mumbuca conduz seu modo de vida em dependência à natureza e com pouca acumulação de capital, realizando diversas atividades em âmbito familiar como: agricultura de subsistência, criação de animais, produção de artesanato, entre outras. Toda forma de manejo é baseada em conhecimentos não científicos, pela construção de técnicas em uniformidade com o meio, utilizando-se de conhecimentos empíricos e sabedoria tradicional que são transmitidos de geração em geração.

Assim, este trabalho buscou identificar os conhecimentos tradicionais da comunidade Mumbuca acerca do uso medicinal de plantas, a fim de buscar correlações com os conhecimentos químicos para propor uma atividade de ensino que seja integradora e dialógica entre os diferentes saberes.

\section{Referencial teórico}

Os saberes tradicionais ou conhecimentos tradicionais são advindos de diversos povos e comunidades tradicionais do Brasil, que incluem: quilombolas, castanheiros, ciganos, seringueiros, povos de matriz africana, ribeirinhos, caatingueiros, pescadores artesanais entre outros (PARANÁ, 2019).

Esses povos são constituídos por cerca de cinco milhões de brasileiros/as, ocupam $1 / 4$ do território nacional e foram reconhecidos em 2007 por meio do Decreto 6.040 (BRASIL, 2007). Ademais, nesse decreto foi instituído a Política Nacional de Desenvolvimento Sustentável dos Povos e Comunidades Tradicionais (PNPCT), que define esses povos como:

[...] grupos culturalmente diferenciados e que se reconhecem como tais, que possuem formas próprias de organização social, que ocupam e usam territórios e recursos naturais como condição para sua reprodução cultural, social, religiosa, ancestral e econômica, utilizando conhecimentos, inovações e práticas gerados e transmitidos por tradição (BRASIL, 2007, p.1).

Os termos "Povos Tradicionais" e "Comunidades Tradicionais" foram apresentados na Conferência Nacional da Igualdade Racial (III CONAPIR, 2011) e é resultado do diálogo promovido pela Secretaria de Políticas de Promoção da Igualdade Racial (SEPPIR) entre lideranças do segmento de todo país e de todas as matrizes. No I Plano Nacional de Desenvolvimento Sustentável dos Povos e Comunidades Tradicionais de Matriz Africana é apresentado uma distinção entre Povos Tradicionais de Matriz Africana e Comunidades Tradicionais de Matriz 
Africana. O primeiro termo refere-se a todos os povos africanos transladados ao Brasil, respeitando suas denominações e históricos originários; enquanto o segundo cita a constituição de africanos e seus descendentes no Brasil, em função do processo de resistência ao escravismo e ao racismo, considerando sua ancestralidade e a relação com as populações locais e meio ambiente (SEPPIR, 2013).

Os saberes tradicionais atribuídos a Povos e Comunidades Tradicionais de Matriz Africana são, na maioria das vezes, atribuídos apenas a sua religiosidade. No entanto, outras práticas e atividades também são de grande notoriedade e incluem o cooperativismo, a oralidade, a corporeidade, a musicalidade, a memória e a ancestralidade, bem como outros valores e saberes trazidos da África e que caracterizam essas comunidades no Brasil (BENITE et al., 2019).

O conhecimento sobre plantas e o poder que lhe é atribuído, tal qual sua utilidade e formas de uso, constituem uma das riquezas essenciais do Candomblé (BENITE et al., 2019). Por meio de seus componentes químicos, as plantas tem um papel funcional e são incorporadas ao cotidiano das comunidades tradicionais como remédios caseiros na forma de chás para aliviar dores, reanimar o estado físico e melhorar a disposição (SIQUEIRA, 1998).

Povos seringueiros também detêm conhecimentos tradicionais sobre plantas medicinais, comumente conhecidas por nomes exóticos como "elixir paregórico" ou "arnica", que sofreram traduções ao longo dos tempos (CUNHA, 2012).

Nos dias atuais, a importância para debates acerca do reconhecimento da ciência tradicional na farmacologia tem sido mais presente. Uma das mais consideráveis contribuições da ciência tradicional está voltada para a agronomia, em particular no que se refere a defensivos naturais e à variedade de espécies cultivadas por populações tradicionais (CUNHA, 2007).

Dessa forma, populações tradicionais são importantes e responsáveis pelo amparo do ambiente natural, uma vez que são detentoras de um saber amplo acerca do lugar onde vivem. Como exemplo têm-se os seringueiros do Alto Juruá, que desenvolveram um modelo sustentável e adequado para a caça, levando em consideração a existência de áreas de refúgio onde não pode ser realizada tal prática. Esse é um modelo tradicional próprio e exclusivo dessa comunidade como meio de preservação de espécies (CUNHA, 2007).

No caso das comunidades tradicionais quilombolas, situadas no Jalapão, a fabricação de artesanato com capim-dourado (que também é cultivado e extraído pela comunidade) é a principal geração de renda, sendo considerado também exemplo de atividade para conservação de áreas naturais do Cerrado (CAVALCANTE, 2018). No entanto, esses quilombos sofrem conflitos junto 
aos órgãos de proteção ambiental e recebem multas por exercerem práticas tradicionais de subsistência (CAVALCANTE, 2018).

Os quilombos tradicionais e contemporâneos são sinônimos de resistência negra, de preservação de saberes e conhecimentos, de ressignificação de memórias e práticas. Tratam-se de espaços que são mantidos e recriados muitos aspectos de origem africana, que se idealizam em projetos futuros e coletivos, se educam, se ensinam e aprendem (HAERTER, NUNES e CUNHA, 2013).

Pacheco (2006) destaca também a importância da figura do(a) griô na estrutura social dos quilombolas, que se refere aos contadores de história e aos que ensinam a tradição em sua comunidade:

Todo (a) cidadão (ã) que se reconheça e seja reconhecido pela sua própria comunidade como herdeiro (a) dos saberes e fazeres da tradição oral e que, através do poder da palavra, da oralidade, da corporeidade e da vivência, dialoga, aprende, ensina e torna-se a memória viva e afetiva da tradição oral, transmitindo saberes e fazeres de geração em geração, garantindo a ancestralidade e identidade do seu povo (PACHECO, 2006, p. 63).

O movimento griô envolve a importância da ancestralidade, objetivando o olhar para o passado como fonte de ensinamentos e cultura. Essa transmissão de conhecimento que acontece de geração em geração tem um peso muito grande em vista do cenário atual da população afroindígena. Hoje a tradição já possui grandes conquistas em espaços de comunidades específicas, porém, um dos desafios agora é levar essa tradição às academias, confrontando fortes preconceitos por parte da sociedade brasileira. Isso porque "as palavras que saem da boca de um griô são consideradas um referencial para a vida dessas populações, uma vez que não apenas representam um elo entre o passado e a atualidade, mas também repercutem sobre o futuro daqueles/as que as ouvem" (SILVA, 2013, [sp]).

Outro aspecto que se destaca nos saberes tradicionais é a inter-relação entre esses conhecimentos e os contextos em que são produzidos e cultivados. Cardoso (2012) exemplifica sobre a pesca artesanal, cujos ciclos da natureza determinam a rotina do pescador, a forma de interação com a natureza e seu trabalho.

Para Cunha (2007), o Brasil se encontra em uma situação privilegiada por ser um país bastante diversificado em relação a recursos e conhecimentos tradicionais, além de ter uma sólida base científica para desenvolver e valorizar esses recursos internamente. No entanto, a autora alerta que o país está perdendo oportunidades de instaurar um regime de colaboração e intercâmbio com suas populações tradicionais, evitando-se violações dos seus direitos sociais, políticos, econômicos e culturais. 
Benite et al. (2019) defendem que uma forma de combater às violências sofridas por comunidades tradicionais, especialmente as Quilombolas, é ressaltando a importância e significância dos conhecimentos tradicionais dessas comunidades sobre, por exemplo, ervas e plantas medicinais no ensino em Química. Uma vez que os conhecimentos tradicional e científico são diferentes formas de interpretação, compreensão e ação sobre as relações humanas e sobre o mundo, o estabelecimento de um diálogo é necessário para melhorar o ensino que vem desconsiderando outros tipos de saberes além do científico em sala de aula (CUNHA, 2007; 2012).

\section{A importância do diálogo entre os saberes tradicionais e científicos}

Os saberes tradicionais vêm ganhando cada vez mais espaços nas escolas, mas ainda são desconsiderados em relação ao conhecimento científico. No que se refere à Educação Escolar Quilombola, é fundamental refletir acerca da necessidade de uma escola brasileira mais plural, cujo pressuposto contemple especificidades históricas, culturais e valores civilizatórios africanos e afrobrasileiros, para que haja uma implementação curricular efetiva (HAERTER, NUNES; CUNHA, 2013).

A educação tem um papel de extrema importância na incorporação da história cultural do continente africano aos sistemas de ensino. A Lei Federal 10.639/03 e as Diretrizes Curriculares Nacionais para a Educação das Relações Étnico-Raciais e História e Cultura Afro-Brasileira e Africana são dispostas pelo MEC para orientação e implementação em todos os níveis de ensino (BRASIL, 2003, 2004).

Porém, apesar da existência dessa lei e passados já 16 anos de sua implantação, ainda é possível observar a falta de compromisso do poder público com a sua efetivação. Ademais, os cursos de licenciatura não preparam de forma adequada os educadores (SOUZA; ALVINO; BENITE, 2011), o que mostra a necessidade de ações político-educacionais de inclusão da cultura africana e afro-brasileira nas mais diversas áreas.

Diante dessas considerações, percebe-se que o diálogo é um elemento importante para a transformação do processo de ensino e aprendizagem, na expectativa de que possa contemplar a discussão inter-relacionando as diversas formas de saberes. Assim, Cunha (2012, p. 442) ressalta que os diálogos entre os saberes pode ser mais "fecundo para o avanço do conhecimento que as trocas entre sistemas de conhecimentos".

Essa contextualização passa por conhecer a realidade do estudante e trazer informações e reflexões sobre sua vivência. A elaboração de materiais didáticos e a realização de atividades em âmbito escolar que abranjam essas experiências cotidianas é uma forma de se fazer isso. Assim, 
entende-se que o diálogo na educação escolar é capaz de transformar os participantes em pessoas críticas, reflexivas e independentes, na medida em que as diferenças entre as experiências e os saberes dos envolvidos são expostas, escutadas e respeitadas.

No entanto, nota-se que a maioria das discussões em sala de aula não há uma inclusão direta dos estudantes e seus saberes durante a formação. Por isso a proposição atividades, que busquem contextualizar informações e saberes culturais de acordo com cada experiência e realidade das comunidades tradicionais, é um caminho para a integração, a participação e o envolvimento direto dos estudantes nessas situações, além de possibilitar a reflexão nos próprios currículos escolares.

Assim, acredita-se que o emprego dos saberes tradicionais no ensino de ciências é uma atitude necessária e humanizadora, a fim de levar em conta a subjetividade do aluno, ajudando-o a se situar em um mundo diverso e plural, contribuindo, portanto, para uma educação científica mais crítica e cidadã.

\section{Metodologia}

Nesta pesquisa adotou-se os princípios da pesquisa etnográfica, que consiste em estudar e entender uma cultura ou a maneira de vida de um grupo de pessoas, revelando "suas ideias, crenças, valores e pressupostos, seus comportamentos e as coisas que fazem" (MOREIRA, 2011, p. 80).

De acordo com Lüdke e André (1986), a pesquisa etnográfica tem três etapas. A primeira é denominada de exploração, que envolve a seleção e a definição do problema, bem como a escolha do local de estudo. Essa etapa permite observar e adquirir melhor conhecimento sobre o fenômeno, possibilitando a seleção de aspectos mais relevantes a serem investigados. Também orienta o processo de coleta de informações e propicia a formulação de uma sequência de hipóteses, que podem sofrer modificações à medida que novos dados são coletados.

Destarte, a escolha da comunidade Mumbuca se deu em função da sua localização (situada no Parque Estadual do Jalapão, um dos parques mais visitados do Brasil) e da importância da comunidade em relação ao turismo devido ao artesanato de capim dourado.

A segunda etapa é conhecida como a busca sistemática dos dados para a compreensão do fenômeno estudado. O que define a relevância do assunto é a forma e o conteúdo da interação verbal dos participantes; padrões de ação e não-ação; traços, registros de arquivos e documentos. A sistematização dos dados foi feita a partir da elaboração de um questionário contendo perguntas a respeito do uso de medicamentos e plantas medicinais pela comunidade (Figura 1). 
Figura 1 - Perguntas elaboradas para a realização da entrevista semiestruturada sobre plantas medicinais

\section{Questionário}

\section{Plantas medicinais}

1 Utilizam plantas como medicamento?

2 Onde surgiu esse conhecimento?

3 Quais plantas mais usam?

4 Quais doenças são tratadas?
5 São aplicados apenas conhecimentos tradicionais?

6 Como esse conhecimento é transmitido?

7 Há alguém exclusivamente responsável pela produção dos medicamentos?

8 Existe algum material na comunidade com informações sobre plantas medicinais?

Fonte: Os autores.

As perguntas foram utilizadas para a realização de entrevista semiestruturada com a matriarca da comunidade, Noemi Ribeiro da Silva, conhecida como Dra. Noemi, bisneta dos fundadores da Comunidade Mumbuca. A gravação (30 min25seg) foi posteriormente transcrita e os resultados avaliados de modo a identificar os saberes tradicionais relacionados ao uso de plantas medicinais e suas correlações com os conhecimentos químicos. Para complementar os dados, registros de campo também foram feitos durante os quatro dias passados na comunidade.

A última etapa é denominada de descoberta, consistindo na interpretação da realidade como uma tentativa de encontrar princípios subjacentes ao fenômeno estudado e de situar as várias observações num contexto mais amplo. Nessa etapa, deve haver uma interação contínua entre os dados reais e as possíveis explicações teóricas, permitindo a estruturação de um quadro teórico dentro do qual o fenômeno pode ser interpretado e compreendido.

A atividade de ensino foi elaborada a partir da produção de um caso investigativo, com as propostas de resolução voltada à aproximação da vivência e saberes tradicionais Mumbuca e o aprendizado científico em química. A atividade inicia-se com a leitura do caso e busca uma discussão por meio de debates coletivos a partir de perguntas chaves que contribuem para o desenvolvimento crítico do estudante. Assim, buscou-se facilitar a compreensão no ensino em química com o objetivo de tornar os estudantes ativos do próprio aprendizado, valorizando a sua experiência de vida durante todo processo. 
É salutar que para o desenvolvimento da pesquisa foi apresentado e explicado o Termo de Consentimento Livre e Esclarecido (TCLE) para os partícipes, que após concordância foi assinado e autorizado a pesquisa.

\section{Resultados e discussão}

A apresentação e discussão dos dados referem-se à entrevista e às conversas informais (registros de campo) com a Matriarca Noemi Ribeiro da Silva, conhecida como Dra. Noemi. A escolha da Dra. Noemi se dá porque foram seus bisavôs que fundaram a Comunidade Mumbuca, como destacada em uma de suas falas:

\footnotetext{
...Começou pelo Pedro Ribeiro (bisavô), aí a mulher dele chama-se Maria Inácia do Carmo... Veio de lá para cá essa geração. Aí, quando a mamãe morreu, antes dela morrer, ela falou assim: ó minha filha, o que tinha que fazer já fiz, tome conta... Sua mãe não tem mais tempo.
}

Dra. Noemi é a terceira geração dos fundadores da Comunidade Mumbuca. Hoje é reconhecida e respeitada como a herdeira dos saberes/fazeres tradicionais, constituindo-se como a principal griô da comunidade. Da mesma forma que aprendeu, a partir do poder da palavra com seus antepassados, sua oralidade é que mantém a memória viva da tradição e da identidade Mumbuca, seja ensinando, vivenciando, dialogando ou aprendendo com o seu povo.

Pacheco (2006) destaca que os conhecimentos que saem da boca de uma griô estabelecem uma conexão entre diferentes tempos, construindo elo entre passado, presente e futuro. Assim como relatados em outros trabalhos, ouvir griôs como Dra. Noemi é parte essencial para conhecer e aprender sobre os saberes tradicionais (PAIVA, 2014; REGIANI, 2014; SANTOS; CAMARGO; BENITE, 2020; SILVA, 2013).

Quando perguntado se existia algum tipo de conhecimento científico aplicado no desenvolvimento de medicamentos na comunidade, Dra. Noemi responde que aprendeu a fazer chá de dipirona (e garrafadas) com sua avó e que todo conhecimento é transmitido pelos mais velhos da comunidade:

\footnotetext{
Não, aqui tudo é passado pelos mais velhos. Minha avó mesmo me ensinou como fazer um chá de dipirona. Colocamos a água para ferver, e depois colocamos as folhas em um copo e tampamos o copo. Não colocamos as folhas pra ferver com a água.
}

$\mathrm{Na}$ resposta apresentada é possível identificar que os saberes da comunidade são transmitidos entre gerações, destacando a origem familiar repassada entre avó e neta, assim como natureza empírica em relação à preparação do chá. A transmissão do procedimento de ferver a 
água primeiro e depois adicionar as folhas de dipirona garante a originalidade do conhecimento, característica de manter a ancestralidade e identidade da sua comunidade (PACHECO, 2006).

Assim como os saberes tradicionais são vistos como informações, também são formas de saber, de criar e fazer. Nesse sentido, é primordial que esse conhecimento se mantenha vivo na memória, pois faz parte da origem, cultura e costumes dos Mumbucas.

Quanto ao uso de plantas medicinais, Dra. Noemi destaca uma diversidade de plantas utilizadas desde as mais conhecidas (capim santo, gengibre, erva cidreira) até espécies específicas do cerrado (samambaia do cerrado, dipirona, candeia):

\footnotetext{
Aqui na comunidade temos dipirona, capim santo, manjericão, gengibre, samambaia do cerrado, erva cidreira, casca de pau do óleo, candeia. Muita coisa que pode nos ajudar... Samambaia do cerrado é muito boa. Limpa o corpo, trata em geral, sara feridas, ajuda a cicatrizar, passa febre. Dipirona, o chá é muito bom também. Candeia que é bom para fazer garrafada da casca e beber para limpar o sangue, sarar ferimentos.
}

Observa-se a presença de conhecimentos sobre uma grande variedade de plantas medicinais. Dentre os saberes tradicionais identificados estão: a relação planta-atuação com benefícios em processos de cicatrização de feridas; controle de febre; e limpeza do sangue. Ademais, destacam-se conhecimentos a respeito do preparo dessas plantas, compreendendo a produção de garrafada da casca da candeia e seus benefícios, a produção do chá de dipirona, além dos diversos usos da samambaia do cerrado.

Godim (2007) destaca que a preparação de chás medicinais é uma das principais manifestações de saber tradicional. Esse saber é parte do desenvolvimento coletivo e cultural de um determinado local, a partir de conhecimentos empíricos e espontâneos que são transmitidos pelas gerações de forma oral. O trabalho de Bastos (2013) também aponta que as comunidades tradicionais possuem um arsenal de conhecimentos sobre o ambiente em que vivem, ressaltando principalmente as propriedades terapêuticas e medicinais de plantas. Isso ressalta a diversidade da medicina tradicional brasileira, fruto de experiências, de vivências e da oralidade transgeracional das comunidades tradicionais.

Especificamente para a planta candeia (espécie Gochnatia polymorpha), diferentes estudos assinalam que as folhas, as flores e as cascas do tronco são usadas na medicina tradicional (preparo de chás ou xaropes) contra resfriados, tosses e outras doenças respiratórias (ARAMBARRI et al., 2008; BUENO et al., 2005; MORS et al., 2000). Tais resultados demonstram a relação direta com os saberes tradicionais supracitados, evidenciando a importância desses saberes para o desenvolvimento de estudos fitoquímicos. 
Dra. Noemi também explica a importância na escolha da árvore candeia, também conhecida como cambará do cerrado, para a produção da garrafada medicinal:

\begin{abstract}
É muito importante a escolha da árvore candeia. É muito importante que seja uma árvore mais antiga, bem mais velha. [...] Como a comunidade procura muito pra fazer a garrafada, a maior parte das árvores já estão com as cascas retiradas. Então precisa observar bem para não descascar cascas novas. No cerrado a candeia é conhecida também como cambará do cerrado... Ao chegar na árvore você limpa bem o tronco, onde você vai retirar a casca. Pega a faca e raspa primeiro, só tira a casca morta por cima (seca). Depois tira as cascas, tira uma de cada vez e coloca uma vasilha embaixo para aparar a seiva que sai vermelha, parece sangue derramando. Quanto mais a árvore for velha mais vermelha sai a casca. Depois que fez a retirada da casca deixa de molho por mais ou menos umas duas semanas curtindo. Você vai observar que a casca vai estar branca. Muitos colocam, mesmo com as cascas brancas, dentro da garrafa. Outros já colocam a seiva curtida na água na garrafa. Eu particularmente coloco toda a casca e o sumo. Para sarar feridas não tem remédio melhor! Limpar o sangue... E assim nós vamos sobrevivendo no cerrado.
\end{abstract}

Nesse trecho verifica-se diversos conhecimentos tradicionais com destaque para: (i) escolha de árvores mais velhas, devido ao envelhecimento conferir propriedades medicinais; (ii) importância da limpeza da região do tronco; (iii) procedimento para a retirada das cascas e da seiva; (iv) procedimento de produção da garrafada; e (v) usos medicinais.

O conhecimento sobre as plantas da região e as possibilidades que lhe são atribuídas, como formas de uso e tratamentos, constituem riquezas essenciais para essa comunidade. Por meio de seus componentes químicos, maneiras de se coletar e o preparo, as plantas possuem um papel funcional, sendo incorporadas ao cotidiano da comunidade como remédios caseiros.

Os resultados apresentados por Nascibem e Viveiro (2015), ao correlacionar os saberes tradicionais de plantas medicinais com os estudos fitoquímicos, demonstram o quanto a ciência está próxima aos conhecimentos de comunidades tradicionais. Concordamos com os autores quando indicam que esses saberes podem ser pontos de partida para ensinar ciências, pois proporcionam diálogos efetivos com contextualização e regionalização.

A sambaíba (Curatella americana L.) também é outra planta utilizada na medicina tradicional da comunidade, associada a benefícios contra constipação, infecção e ao sistema reprodutor feminino:

Meu amigo, meu amigo... O cerrado é largo, o cerrado é grande! Tem muita opção de remédio no cerrado. No cerrado temos a samambaia... Aquele que conforme você toma o chá ou toma banho...é um bom remédio pra constipação, pra útero de mulher, infecção... Mulher parida. 
Nesse excerto, identificam-se mais dois aspectos ligados aos saberes tradicionais: (i) a experiência cultural de Dr. Noemi sobre a importância do cerrado para a comunidade; e (ii) a amplitude do conhecimento de usos de diversas plantas.

De acordo com Cunha (2007), quanto maior a variedade entre esses povos e comunidades, maior a diversidade nas maneiras de enxergar a realidade e de sistematizá-la. Dessa forma, alguns saberes possuem sentido e validade apenas em âmbito local.

Quanto à amplitude do saber tradicional, é importante destacar a própria identidade e ancestralidade da comunidade. Trabalhos como de Cardoso (2012), por exemplo, reforçam o reconhecimento de herdeiros de saberes e fazeres da tradição oral em comunidades tradicionais, uma vez que garantem a transmissão dos conhecimentos e a identidade cultural do seu povo.

Ao se dialogar com alguns estudos farmacológicos das espécies de samambaia, o uso da planta em tratamentos anti-inflamatórios e anti-hipertensivos corrobora com tais relatos tradicionais. Além disso, Toledo et al. (2015) descreveram atividades antimicrobianas do extrato etanólico da casca de sambaíba e eficácia antifúngica contra espécies Candida sp. Essas atividades demonstraram algum potencial medicinal referente a essa planta, reforçando novamente o uso dos saberes tradicionais para estudos científicos, uma vez que é a partir desses conhecimentos que se pesquisa para maior compreensão dos benefícios e futuros medicamentos.

Tais resultados se dialogam com o proposto por Kovalski, Obara e Figueiredo (2011), que ao investigarem como as professoras trabalham o saber tradicional e o conhecimento científico sobre plantas medicinais, em uma escola rural no município de Maringá-PR, mostraram que as estratégias de ensino promovidas pelas professoras buscam oferecer aos estudantes uma comparação entre os diferentes saberes.

Nessa mesma ideia, os saberes sobre as plantas e as produções de chá e garrafada identificados também possibilitam um diálogo mais aprofundado com os conhecimentos científicos. Esse diálogo pode ser feito por meio de propostas de atividades na própria escola da comunidade Mumbuca, reforçando os saberes tradicionais e fortalecendo a relação com os saberes científicos em prol de uma formação mais integral.

$\mathrm{Na}$ Tabela 1 se apresenta os principais saberes tradicionais identificados sobre à temática plantas medicinais, mostrando as possíveis correlações com conceitos químicos que podem ser debatidos em atividades futuras. 
Tabela 1 - Possíveis inter-relações entre os saberes sobre plantas medicinais da comunidade Mumbuca e o conhecimento químico para a proposição da atividade de ensino

\begin{tabular}{|l|l|}
\hline Saberes tradicionais sobre plantas medicinais & \multicolumn{1}{|c|}{ Conhecimentos químicos } \\
\hline Variedade de plantas e seus usos & $\begin{array}{l}\text { Conceituais: moléculas, substâncias e } \\
\text { propriedades. }\end{array}$ \\
\hline Produção de garrafada da casca da candeia & $\begin{array}{l}\text { Procedimentais: preparo de amostra, extração por } \\
\text { solvente, filtração. } \\
\text { Conceituais: interações intermoleculares, } \\
\text { polaridade, solubilidade, efeito da temperatura, } \\
\text { solução, concentração. }\end{array}$ \\
\hline Produção de chá de dipirona & $\begin{array}{l}\text { Procedimentais: preparo da amostra, infusão, } \\
\text { filtração. } \\
\text { Conceituais: interações intermoleculares, } \\
\text { polaridade, solubilidade, efeito da temperatura, } \\
\text { concentração. }\end{array}$ \\
\hline
\end{tabular}

Fonte: $\operatorname{xxxx}$

É possível correlacionar os saberes tradicionais e científicos envolvendo tanto conhecimentos procedimentais quanto conceituais. Por exemplo, ao propor uma atividade na escola com a elaboração de um chá feito na comunidade, pode-se introduzir uma discussão sobre diversos conceitos químicos, fomentando debates sobre as propriedades e as funcionalidades do processo e fortalecendo as práticas do povoado.

Ao fazer isso se resgata e valoriza os saberes tradicionais para o interior das salas de aula, estabelecendo uma maior relevância para o Ensino de Ciências. Pode-se citar, por exemplo, a Farmacopeia, que é uma obra que contém referência teórica para a indicação segura de remédios caseiros no dia a dia das comunidades tradicionais. Além disso, oferece conhecimentos tradicionais associados à biodiversidade e o acesso a esses conhecimentos para fins de pesquisa científica e desenvolvimento de produtos comerciais (LOIOLA et al., 2009).

Tecendo relações entre os saberes tradicionais e científicos: uma proposta de ensino multicultural

O caso investigativo "Lourenço e o chá de dipirona" (Figura 2) foi feito a partir da identificação dos saberes tradicionais da comunidade Mumbuca sobre plantas medicinais supracitados. Para isso, utilizou-se do conceito de tema gerador para estabelecer diálogos entre a vivência do povoado Mumbuca e a ciência/química. O que se coloca em discussão é a importância do conhecimento tradicional do preparo do chá de dipirona para o tratamento de doenças na 
comunidade, bem como a oralidade como a principal forma de transmissão desse saber. Os conceitos de química a serem abordados a partir dessa atividade envolvem desde os procedimentos empregados no preparo (extração, filtração, decantação) até as propriedades químicas e bioativas das moléculas presentes no chá.

Figura 2 - Caso investigativo elaborado para a proposta de atividade de ensino

\section{LOURENÇO E O CHÁ DE DIPIRONA}

\section{“...são importantes..." TUM! de novo.}

Lourenço, que tem um pouco mais de 13 anos e é um pouco alto para a sua idade, tem bochechas grandes e olhos quase sumindo no rosto. Durante a explicação da professora de ciências sua dor de cabeça parece aumentar cada vez mais, levando-o a pensar que todas aquelas informações e nomes de plantas são a verdadeira causa da explosão em seu crânio. Quando não aguenta mais de dor, Lourenço interrompe a professora:

- Professora, estou zonzo de dor de cabeça, posso ir para casa?

- Tudo bem Lourenço. Mas você sabe o motivo dessa dor? Anda forçando as vistas no celular e na televisão? Pode ser isso também! Vá para a casa e aproveita que a médica está hoje na vila para fazer uma consulta. Mas ao chegar casa, peça para tua mãe preparar algum chá usando as plantas que ela tem lá, quem sabe assim diminuam as dores até ir à médica.

- É verdade, professora. Esse final de semana fiquei até tarde vendo videoaula e estudando matemática pelo celular, aí já viu né? Forcei as vistas. Vou ligar para a minha mãe para avisá-la, obrigado!

Enquanto Lourenço separa seus materiais escolares para avisar sua mãe que está indo pra casa, a aluna Ana Beatriz diz que sua avó sempre prepara chás das ervas que cultiva em casa e que quase nunca toma remédio, pois para tudo sua avó conhece uma erva ou chá.

- Tá vendo, pessoal! - Diz a professora - A avó da Ana, com a experiência de vida que tem, conhece a importância das plantas e o potencial medicinal que elas têm. Quem aqui já tomou chá de alho pra resfriado ou boldo pra dor de barriga?

Boa parte da turma levanta a mão e então a professora diz que muitas plantas foram e ainda são bases para a produção de remédios vendidos nas farmácias.

- Hoje, no SUS, temos diversos remédios disponíveis feitos a partir de plantas! Como o fitoterápico de maracujá, ou Passiflora, que tem princípios que ajudam a relaxar e ter uma boa noite de sono. daqueles!

- Nossa professora, por isso que sempre que a minha mãe faz suco de maracujá no almoço eu tiro um cochilo

A sala toda ri, até mesmo Lourenço enquanto deixa a sala de aula.

Lourenço mora com sua mãe num vilarejo muito distante da cidade e com pouco acesso a serviços sociais essenciais. Sempre fora tratado a partir das plantas que sua mãe, Dona Ângela, cultiva em casa. Ela é benzedeira, rezadeira e é conhecida na região pelo uso de plantas como medicamento. Sempre que a comunidade precisa de atendimento médico e não tem na vila, recorrem a ela que se alegra em preparar suas medicações. Nessa comunidade Dona Ângela já salvou muitas vidas com o conhecimento que herdou de seus avós no uso de plantas medicinais, mas Lourenço nunca sabia como essas preparações são feitas e suas ações no organismo.

Ao chegar em casa, Lourenço fala:

- Mãe, tô com uma dor muito forte de cabeça e precisei voltar pra casa pois não conseguia nem prestar atenção na aula.

— Tudo bem, meu filho. Já liguei no postinho pra gente marcar uma consulta com a médica essa tarde. Você quer que a mamãe prepare um chá de dipirona pra já ir aliviando as dores?

- Por favor, mãe. Obrigado!

Enquanto dona Ângela preparava o remédio para Lourenço, ele tomou banho e se deitou numa rede de dormir que se estendia preguiçosa na área perto do fogão a lenha. Depois de tomar o chá, Lourenço almoçou e se deitou até o horário de ir à consulta com a mãe. No caminho ao posto de saúde, Lourenço disse que já se sentia um pouco melhor e sugeriu à mãe que voltassem para a casa. Dona Ângela então disse que o remédio era só para aliviar o sintoma, mas que era importante uma consulta para averiguar a causa da dor.

Durante a consulta com a médica, sua mãe comentou sobre chá de dipirona que havia dado para o filho mais cedo e que ajudou a aliviar a dor que estava muito forte. A médica elogiou a mãe em ter tratado os sintomas com o chá de dipirona e explicou que o princípio ativo é o mesmo do medicamento que seria administrado ali no posto de saúde. Comentou que ter conhecimento sobre as plantas medicinais é importante para tratar sintomas leves em casa, assim como saber utilizar a planta durante os preparos para garantir a eficácia do medicamento.

- Bom, os sintomas já foram tratados pela sua mãe, agora vamos averiguar a causa da dor. Vou fazer um encaminhamento para o oftalmologista.

Lourenço sentiu tanto orgulho dos conhecimentos de sua mãe, elogiados pela médica, que durante a volta para casa, pediu para ela ensiná-lo a preparar o chá de dipirona, assim como ela aprendera com seus avós.

Considere que você seja a mãe de Lourenço. Como ensinaria os procedimentos para a preparação do chá de dipirona e qual a importância desse conhecimento?

Fonte: $\mathrm{xxx}$ 


\section{Sugestão de desenvolvimento}

Sugere a utilização de 4 aulas para o ensino médio com o tema principal "Chás medicinais e a sua importância para a comunidade Mumbuca". O objetivo é que os estudantes consigam interrelacionar o conhecimento tradicional no preparo de chás medicinais com o conhecimento científico (química), valorizando a sua importância para a comunidade.

\section{Aula 1 - Interpretando o caso para resolução}

Ler o caso com os estudantes em sala de aula e separá-los em grupos de três pessoas. Pedir para que interpretem as informações do texto e discutam de que forma a mãe de Lourenço ensinaria os procedimentos no preparo do chá para seu filho. Um possível guia para a análise do caso seria:

- Do que se trata o caso?

- Há relação entre a história e a sua vida?

- Faz uso de chás para algum sintoma ou doença?

- Quais os chás que mais usa?

- Você aprendeu a preparar chás com alguém da sua família?

- Qual a importância desses conhecimentos na comunidade Mumbuca?

Ao final da aula, todos os grupos discutirão sobre a importância de cada etapa e do conhecimento sobre os chás medicinais e o seu preparo. Como atividade de pesquisa pode-se sugerir que em casa, os estudantes leiam o caso para os familiares (pais, avós ou pessoas mais velhas) e perguntem-lhes se já fizeram uso de chá para aliviar algum sintoma. Se sim, perguntar quais os chás que mais utilizam, sobre o processo de preparo e com quem eles aprenderam.

\section{Aula 2 - Relacionando o caso com a vida cotidiana}

Os estudantes formarão grupos de 3 integrantes, diferentes dos grupos da aula passada. Cada grupo debaterá sobre o que foi conversado em casa, elaborando uma tabela com os nomes das plantas que cada familiar descreveu, os pontos diferentes e em comum entre os processos de preparo.

Em seguida, cada grupo apresentará suas informações para socialização. A partir daí, será discutido a diversidade dos conhecimentos tradicionais da comunidade Mumbuca, destacando a importância desses conhecimentos e buscando fazer relação com os conhecimentos científicos 
sobre os processos envolvidos (extração, filtração, decantação) e conceitos químicos em cada preparação descrita.

Como atividade de pesquisa, o professor ou a professora poderá solicitar que os/as estudantes pesquisem sobre a planta dipirona. Depois, que encontrem a planta na comunidade e levem para a próxima aula uma quantidade para realizar os procedimentos de preparação do chá.

\section{Aula 3 - Preparando o chá medicinal}

Os/as estudantes realizarão uma atividade prática da preparação do chá de dipirona, apontada no caso, com a orientação do/a professor/a sobre manuseios das vidrarias e dos processos.

A atividade de pesquisa pode focar na busca de outras plantas medicinais usadas na comunidade que possuem procedimentos semelhantes ao que realizaram na aula prática, indicando o nome popular e científico da planta, assim como o principal uso medicinal.

\section{Aula 4 - Relacionando o preparo do chá com conceitos químicos}

$\mathrm{O} / \mathrm{a}$ professor/a poderá iniciar perguntando aos estudantes sobre quais conceitos de química estão envolvidos no processo de preparação do chá de dipirona, fazendo uma discussão ampla com a turma e direcionando para a resolução do caso (retomar o problema proposto no caso para esse direcionamento) que será entregue para finalizar a avaliação.

Poderá relembrar cada conceito sobre o processo de preparação, discutido na aula anterior, e introduzir novos conceitos que interligam os princípios que elucidam o poder medicinal de cada planta, como por exemplo, os conceitos de moléculas bioativas, conformação e estereoquímica e forças intermoleculares, além de salientar sobre a importância dos conhecimentos tradicionais e de como eles são transmitidos.

Como atividade avaliativa, o professor poderá propor que os estudantes representem (em desenho) as etapas envolvidas no preparo do chá medicinal, como se fosse feito pela mãe de Lourenço, e que descrevam os processos envolvidos; para que depois apresentem para os demais colegas discutindo sobre a importância desse conhecimento para o povo da comunidade Mumbuca, de acordo com a sua perspectiva. 


\section{Considerações finais}

Os resultados apontam que a comunidade Mumbuca, representada pela sua matriarca, possui diversos saberes tradicionais relacionados às plantas medicinais. Desde uma variedade de espécies que cumprem com esse papel até a seleção da planta para preparação de chás e/ou garrafadas.

Os saberes tradicionais sobre as plantas e as produções de chá e garrafada proporcionam autonomia a comunidade e demonstram a importância das próprias experiências e do saber-fazer em práticas tradicionais. Observa-se que os saberes da comunidade são transmitidos de geração para geração de forma anônima, pois mesmo quando Dra. Noemi diz ter aprendido sobre a preparação de chás com sua avó, não se sabe a fonte original do conhecimento adquirido por ela. Isso é atribuído ao conhecimento empírico e acumulativo, caracterizado pela perspectiva da comunidade sobre a sua realidade e vivência.

A contextualização dos saberes tradicionais permite conhecer a realidade do estudante e trazer informações e reflexões sobre as suas vivências, transformando a experiência de aprendizagem em uma prática democrática. Por isso, a proposição da atividade de ensino com o caso, que resgata a relevância desses saberes, visa possibilitar aos estudantes a oportunidade da construção de conhecimentos significativos por meio de práticas integrativas que corroboram sua perspectiva a respeito das plantas medicinais.

Como contribuição, a proposta pedagógica do presente trabalho permite que os educadores enxerguem a possibilidade de inserção de um plano de ensino que considere a realidade desses povos e da importância da inserção das suas vivências em âmbito escolar, tornando o aprendizado uma prática possível e significativa aos povos tradicionais.

\section{Referências}

ALCANTARA, R. G. L.; JOAQUIM, R. H. V. T.; SAMPAIO, S. F. Plantas medicinais: o conhecimento e uso popular. Revista de APS, v. 18, n. 4, 2015.

ALMEIDA, R. O. Ajofe e alcoometria: as escolas diante das mudanças socioculturais ligadas à produção de cachaça artesanal na microrregião de Abaíra, Bahia, Brasil. Ciência \& Educação, Bauru, v. 18, n. 1, p. 187-214, 2012.

ARAMBARRI, A. M. et al. Leaf anatomy of medicinal shrubs and trees from Misiones forest of the Paranaense Province (Argentina). Boletin de la Sociedad Argentina de Botanica, Buenos Aires, v. 43, n. 1, p. 31-60, 2008.

BENITE, A. M. C. et al. Dai-me agô (licença) para falar de saberes tradicionais de matriz africana no ensino de química. Quimica Nova, São Paulo, v. 42, n. 5, p. 570-579, 2019. 
BRASIL. Lei $n^{\circ}$ 10.639, de 9 de janeiro de 2003. Altera a Lei no 9.394, de 20 de dezembro de 1996, que estabelece as diretrizes e bases da educação nacional, para incluir no currículo oficial da Rede de Ensino a obrigatoriedade da temática "História e Cultura Afro-Brasileira", e dá outras providências. Disponível em: http://www.planalto.gov.br/ccivil_03/leis/2003/110.639.htm. Acesso em: 18 ago. 2021.

BRASIL. Ministério da Educação. Diretrizes Curriculares Nacionais para a Educação das Relações ÉtnicoRaciais e para o Ensino de História e Cultura Afro-Brasileira e Africana. Brasília: MEC, 2004.

BRASIL. Decreto $n^{\circ}$ 6.040, de 7 de fevereiro de 2007. Institui a Política Nacional de Desenvolvimento Sustentável dos Povos e Comunidades Tradicionais. Disponível em: http://www.planalto.gov.br/ccivil_03/_ato2007-2010/2007/decreto/d6040.htm. Acesso em: 18 ago. 2021.

BUENO, N. R. et al. Plantas medicinais usadas pelas populações indígenas Kaiowá e Guarani na Reserva de Carapó, Mato Grosso do Sul, Brasil. Acta Botanica Brasilica, Brasília, v. 19, p. 39-44, 2005.

CAVALCANTE, J. P. R. Regularização territorial do quilombo mumbuca: identidade e memória como fundamento da propriedade quilombola. 141 f. 2018. Dissertação (Mestrado em Direitos Humanos) - Universidade Federal do Goiás, Goiânia, 2018.

CARDOSO, M. B. da C. Saberes ribeirinhos quilombolas e sua relação com a educação de jovens e adultos da comunidade de São João do Médio Itacuruçá, Abaetetuba/PA. 161 f. 2012. Dissertação (Mestrado em Educação) - Universidade Federal do Pará, Belém, 2012.

CUNHA, M. C. Relações e dissensões entre saberes tradicionais e saber científico. Revista USP, $\mathrm{n}$. 75, p. 76-84, 2007.

CUNHA, M. C. da. Questões suscitadas pelo conhecimento tradicional. Revista de Antropologia, São Paulo, v. 55, n. 1, p. 439-464, 2012.

DIEGUES, A. C. O mito moderno da natureza intocada. 5. ed. São Paulo: Hucitec, 2004.

GONDIM, M. S. da C. A inter-relação entre saberes científicos e saberes populares na escola: uma proposta interdisciplinar baseada em saberes das artesãs do Triângulo Mineiro. 2007. 176 f. Dissertação (Mestrado Profissionalizante em Ensino de Ciências) - Programa de Pós-Graduação em Ensino de Ciências, Universidade de Brasília, Brasília, 2007.

HAERTER, L.; NUNES, G. H. L.; CUNHA, D. T. R. Refletindo acerca da contribuição da cultura quilombola aos currículos da educação básica brasileira, através da presença da história da África e afro-brasileira. Identidade!, São Leopoldo, v. 18, n. 3, p. 267-278, 2013.

KOVALSKI, M. L.; OBARA, A. T.; FIGUEIREDO, M. C. Diálogo dos saberes: o conhecimento científico e popular das plantas medicinais na escola. In: VIII Encontro Nacional de Pesquisa em Educação em Ciências. Campinas, p. 1-13, 2011. Disponível em:

http://abrapecnet.org.br/atas_enpec/viiienpec/resumos/R1647-1.pdf. Acesso em: 14 maio 2021.

LOIOLA, A. A. et al. Farmacopéia Popular do Cerrado. Goiás: Articulação Pacari, 2009.

LÜDKE, M.; ANDRÉ, M. E. D. A. Pesquisa em educaşão: abordagens qualitativas. São Paulo: EPU, 1986. 
MOREIRA, M. A. Metodologias de pesquisa em ensino. São Paulo: Livraria da Física, 2011.

NASCIBEM, F. G.; VIVEIRO, A. A. Saberes populares consCiência: uma investigação sobre a medicina popular. In: X Encontro Nacional de Pesquisa em Educaşão em Ciências, Florianópolis, p. 1-9, 2015. Disponível em: < http:/ /www.abrapecnet.org.br/enpec/Xenpec/anais2015/resumos/R0773-1.PDF>. Acesso em: 14 maio 2021.

PACHECO, L. Pedagogia Griô: a reinvenção da roda da vida. Lençóis: Grãos de luz e Griô, 2006.

PAIVA, A. de S. Conhecimentos tradicionais e ensino de biologia: Desenvolvimento colaborativo de uma sequência didática sobre reprodução vegetal. 2014. 226 f. Dissertação (Mestrado em Educação) Universidade Federal da Bahia, Salvador, 2014.

PARANÁ. Departamento de Direitos Humanos e Cidadania - DEDIHC. Povos e Comunidades tradicionais. Curitiba: Secretaria da Justiça, Trabalho e Direitos Humanos, 2019.

PINHEIRO, P. C.; GIORDAN, M. O preparo de sabão de cinzas em Minas Gerais, Brasil: do status de etnociência à sua mediação para a sala de aula utilizando um sistema hipermídia etnográfico. Investigações em Ensino de Ciências, Porto Alegre, v. 15, n. 2, p. 355-383, 2010.

REGIANI, A. M. Conhecimento tradicional e quimica: possíveis aproximações. Curitiba: CRV, 2014.

RESENDE, D. R.; CASTRO, R. A. de; PINHEIRO, P. C. O saber popular nas aulas de química: relato de experiência envolvendo a produção do vinho de laranja e sua interpretação no ensino médio. Química Nova na Escola, São Paulo, v. 32, n. 3, p. 151-160, 2010.

SANTOS, M. A.; CAMARGO, M. J. R.; BENITE, A. M. C. Vozes Griôs no Ensino de Química: Uma Proposta de Diálogo Intercultural. Revista Brasileira de Pesquisa em Educação em Ciências, Belo Horizonte, v. 20, p. 919-947, 2020.

SEPPIR (Secretaria de Políticas de Promoção da Igualdade Racial / Secretaria de Políticas para Comunidades Tradicionais (2013). I Plano Nacional de Desenvolvimento Sustentável dos Povos e Comunidades Tradicionais de Matriz. Africana. Disponível em:

http://portal.iphan.gov.br/uploads/ckfinder/arquivos/plano_nacional_desen_sustentavel_povo s_comunidades_trad_matriz_africana.pdf. Acesso em: 14 maio 2021.

SILVA, C. S. Do griô ao vovô: o contador de histórias tradicional africano e suas representações na literatura infantil. Nau Literária, v. 9, n. 2, p. 1-13, 2013.

SIQUEIRA, M. de L. Agô Agô Lonan - Mitos, ritos e organizações em terreiros de Candomblé da Bahia. Belo Horizonte: Mazza Edições, 1998.

SOUZA, E. P. L.; ALVINO, A. C. B. BENITE, A. M. C. Ensino de ciências e identidade negra: estudos sobre a configuração da ação docente. In: VIII Encontro Nacional de Pesquisa em Educação em Ciências e I Congreso Iberoamericano de Investigación en Enseñanza de las Ciencias, Campinas, p. 1-12, 2011. Disponível em: http://abrapecnet.org.br/atas_enpec/viiienpec/resumos/R0749-1.pdf. Acesso em: 14 maio 2021.

TOLEDO, C. E. M. de et al. Antifungal properties of crude extracts, fractions, and purified compounds from bark of Curatella americana L. (Dilleniaceae) against Candida species. EvidenceBased Complementary and Alternative Medicine, Oxford, v. 2015, p. 1-9, 2015. 